\title{
LA CONSTRUCCIÓN HOTELERA EN LA ESPAÑA DEL FINAL DE LA AUTARQUÍA. UNA APROXIMACIÓN A TRAVÉS DE LA REVISTA NACIONAL DE ARQUITECTURA
}

\author{
HOTEL CONSTRUCTION IN SPAIN AT THE END OF THE \\ AUTARCHY. AN APPROACH THROUGH THE NATIONAL \\ ARCHITECTURE MAGAZINE
}

\author{
CARMEN ADAMS FERNÁNDEZ \\ Universidad de Oviedo
}

\section{RESUMEN}

La construcción hotelera, en la España de finales de los años 50 del siglo XX, muestra una clara apuesta por el funcionalismo y la modernidad. Se evidencia -a través de la Revista Nacional de Arquitectura editada en Madrid- que la arquitectura turística se adscribe en esta etapa a las tendencias internacionales del momento. Esto se hace patente además por la aparición de ejemplos españoles en catálogos europeos, junto a hoteles de reconocida calidad arquitectónica de otros países. Modernidad entendida además como sobriedad funcional en los exteriores; lo que contrata con interiores donde se recrea un gusto Decó lujoso. Así, las tendencias vanguardistas están presentes en España desde la posguerra, lo que demuestra cómo las panoplias y regresiones de la Autarquía no impidieron el mantenimiento de una línea innovadora en la arquitectura nacional que venía de la etapa anterior.

Palabras clave: Arquitectura, Hotel, Turismo, Funcionalismo. 


\begin{abstract}
Hotel construction in Spain, in the late 50s of the 20th century, shows a clear commitment to functionalism and modernity. It is evidenced - through the National Architecture Magazine published in Madrid - that tourism architecture is attached at this stage to the international trends of the moment. This is also evident by the appearance of Spanish examples in European catalogs, among hotels of renowned architectural quality from other countries. Modernity also understood as functional sobriety in the exteriors; what hires with interiors where he recreates a luxurious taste Decó. Thus, avantgarde trends are present in Spain since postwar period, which demonstrates that regressions of the Autarchy did not prevent the maintenance of an innovative line in the national architecture that came from the previous stage.
\end{abstract}

Keywords: Architecture, Hotel, Tourism, Functionalism. 
"La casa tiene que gustar a todos, contrariamente a la obra de arte, que no tiene que complacer a nadie. La obra de arte es un asunto privado del artista. La casa no lo es."

"Sólo existe una pequeña parte de la arquitectura que pertenezca al arte: el monumento funerario y el monumento conmemorativo. Todo lo demás, lo que sirve para un fin, debe quedar excluido del reino del arte."

Adolf Loos

\section{INTRODUCCIÓN}

La modernidad desplegada en los proyectos para establecimientos hoteleros publicados en la Revista Nacional de Arquitectura durante los años 50 evidencia una eclosión del funcionalismo y las vanguardias en la arquitectura española del momento, impensable una década antes. Modernidad que entronca necesariamente con los años previos a la Guerra Civil. De hecho, DOCOMOMO ibérico dedica en 2003 un monográfico con el elocuente título Arquitectura moderna y Turismo: 1925-1965 ${ }^{1}$. La elección del periodo no es en absoluto aleatoria. La profunda transformación de la arquitectura que se nota a partir de la década de los 20 se mantendrá -pese a los historicismos y panoplias varias que salpican los edificios españoles en los '40- hasta que el desarrollismo de los 70 nos obligue a buscar otras claves para entender la realidad. Y ello en lo que a turismo se refiere, tiene una doble vertiente; pues a lo antedicho se ha de añadir el imparable inicio de sol y playa, la masificación y la accesibilidad de vacaciones para todos los niveles sociales (algo que sólo se había enunciado en proyectos piloto durante los años 20 y 30 ).

Modernidad entendida además como sobriedad funcional en los exteriores. Lo que contrata con interiores donde se recrea un gusto Decó lujoso ${ }^{2}$.

El interés por la construcción turística española de estos años es así evidente, existiendo publicaciones de ámbito internacional que reseñan obras de este tipo, entre las más destacadas de Europa ${ }^{3}$. Así por Así por ejemplo, Paulhans Peters en Hoteles y Colonias veraniegas, hace referencia a diversos

1 Actas IV Congreso. Fundación DOCOMOMO Ibérico Arquitectura moderna y Turismo: 1925-1965, Valencia, 2003.

2 Es interesante reseñar que esa tendencia a los interiores Decó en las propuestas hoteleras de los cincuenta reaparece en España en hoteles urbanos a partir de edificios del siglo XX rehabilitados. Así en el hotel que próximamente abrirá sus puertas en la Plaza de España de Madrid, o el recién inaugurado Le Modern en Gijón, a partir de un edificio art decó de Manuel Del Busto.

3 PETERS, Paulhans: Hoteles y Colonias veraniegas, Guatavo Gili, Barcelona, Munich, 1970. 
modelos españoles entre una amplia muestra de edificios de diversos lugares de Europa.

Para este trabajo se han escogido un conjunto de inmuebles hoteleros construidos en España durante la década de los 50 y primeros 60, que tuvieron interés para ser reseñados en la Revista Nacional de Arquitectura ${ }^{4}$.

\section{HOTEL PARK. BARCELONA}

"El emplazamiento del edificio en una de las zonas más antiguas de la ciudad, suscitó el clásico dilema de moderno o antiguo. Desde luego, este dilema no se lo planteó el arquitecto, sino aquellos que creen que la arquitectura no es una cosa viva, sino una farsa...En definitiva, no había para tanto, pues se trata de un edificio corriente sin ninguna pretensión, como deben ser los edificios que se hacen cada día". Así finaliza el artículo dedicado al Hotel Park (195054) de Barcelona, en la Revista Nacional de Arquitectura, que firma su proyectista, Antonio de Moragas Gallisá (que contó con la colaboración de Francesc Riba i Salas) en $1957^{5}$. Toda una declaración de principios cuando España apenas iniciaba el final de la Autarquía, y una muestra más de la apuesta de Moragas por la modernidad.

Era en España un momento de transición al desarrollismo, que en arquitectura se evidencia con grupos como el $R$ de Moragas, Coderch, Valls, Sostres, Bohigas... cuyo objetivo es en mostrar los logros y avances internacionales, de los que se hará eco la Revista Nacional de Arquitectura.

4 Este tipo de fuentes hemerográficas se evidencian muy interesantes para el estudio del devenir de las corrientes arquitectónicas. Ver las actas publicadas del Congreso Internacional de Historia de la Arquitectura Española, celebrado en 2012 y dedicado a Las revistas de arquitectura (1900-1975).

5 DE MORAGAS GALLISÁ, Antonio: "Hotel Park en Barcelona", Revista Nacional de Arquitectura $\mathrm{n}^{\circ}$ 182, Madrid, Febrero, 1957 
En lo referente a construcción hotelera, la España de posguerra ${ }^{6}$ intentará hacer frente a las notables carencias, en una clara política de atraer visitantes para obtener divisas, siguiendo las pautas ya fijadas por el Marqués de la Vega Inclán. Así, en julio de 1951 se creó el Ministerio de Información y Turismo. El primer equipo ministerial, que se mantendría en el cargo hasta el mes de julio de 1962, lo dirigió Gabriel Arias Salgado. Tal como señala Pellejero Martínez "durante el periodo en el que Arias Salgado estuvo al frente del Ministerio, una etapa marcada, entre otras cosas, por el fin del aislamiento económico y político de la España de Franco, el progresivo, aunque algo lento, abandono de la política autárquica, y el Plan de Estabilización de 1959, el turismo experimentó en nuestro país un notable crecimiento. En el año 1951 el número de visitantes fue de 1,26 millones y el de ingresos por turismo de 29,51 millones de dólares. Diez años después, nos visitaron 7,45 millones e ingresamos 384,63 millones de dólares. En ese mismo periodo de tiempo, el número de establecimientos hoteleros (hoteles y pensiones) se incrementó un 117,8 por ciento y el de plazas un 105,8 por ciento".

$\mathrm{Y}$ es en ese contexto en el que se ha de comprender la construcción de establecimientos como el Hotel Park, en un lugar tan estratégico como supone la cercanía a la barcelonesa Estación de Francia, en pleno barrio de El Born.

La Fundación DOCOMOMO Ibérico entregó el Día de la Arquitectura 2012 la placa informativa al Hotel Park, al ser considerado un edificio paradigmático de la arquitectura moderna. Está además inscrito como Bien de Interés Cultural (BCIL) en el In-

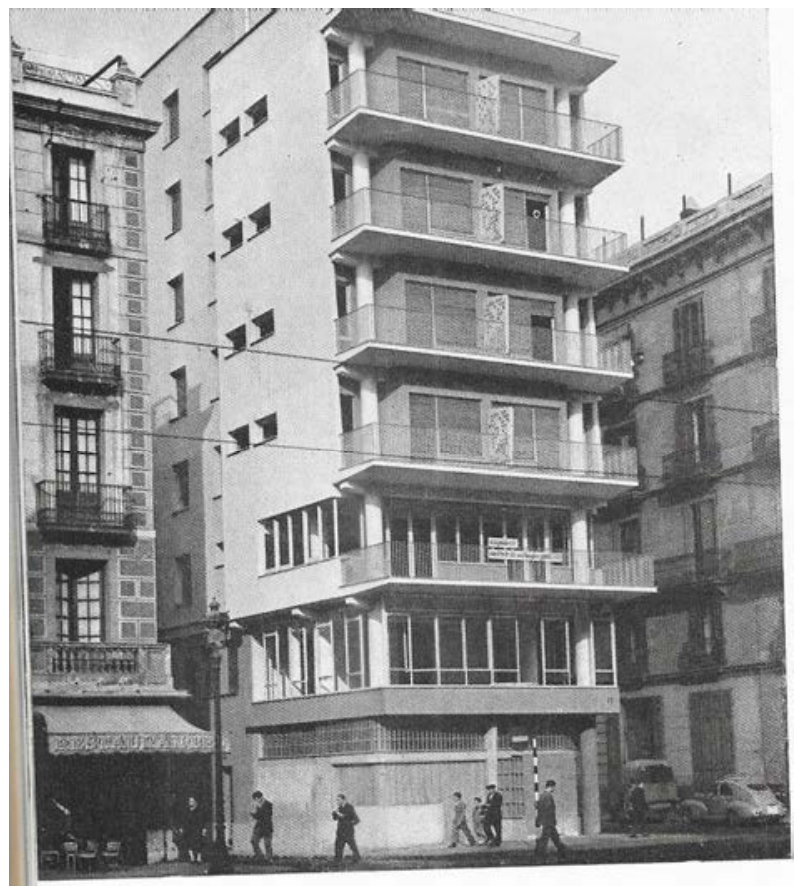
ventario del Patrimonio

6 PELLEJERO MARTÍNEZ, Carmelo: "La política turística en la España del siglo XX: una visión general", en Historia Contemporánea 25, 2002, 233-265 
catalán. Por su estructura, por la composición de la fachada, con elementos estructurales a la vista, y por los materiales utilizados está considerado como uno de los edificios de mayor interés arquitectónico de los construidos en Barcelona durante los años cincuenta del siglo XX.

El inmueble fue reformado en 1991 bajo la dirección del hijo de Moragas, Antoni de Moragas Spa y por Irene Sánchez.

Posteriormente, en 2012 GCA Arquitectes Associats, con Josep Riu al frente del proyecto, reconvierte el antiguo restaurante " $\mathrm{ABaC}$ ", en un espacio informal de tapas de autor, TEN'S, con capacidad para 60 comensales. El restaurante sirve a la vez de comedor buffet de desayunos del Hotel Park. Paralelamente se desarrolló el proyecto de recepción y bar del hotel, al igual que el concepto de habitaciones. Se buscó una imagen unitaria de todo el conjunto, para dotarlo de entidad y a su vez convivir e integrarse con la arquitectura racionalista del edificio.

Previamente Moragas había hecho un proyecto para el mismo cliente y en el mismo emplazamiento, en el que además de hotel había oficinas y almacén. En la solución definitiva del hotel, en cada uno de los pisos superiores, un corredor central da acceso a las habitaciones a los dos lados. En la planta baja se encuentra el vestíbulo y el bar-restaurante, y en las dos plantas inmediatas, los salones y comedores, con grandes vitrinas que contrastan con las aberturas dosificadas en las habitaciones.

Tal como señala Vendrell Felici "El lenguaje utilizado en este edificio se basa en la sistematización de una delimitada serie de elementos domésticos de la vivienda barcelonesa: ventanas, balcones, alféizares, forjados y muros trazados de manera rigurosa, pensados de manera que cada elemento constructivo y funcional se exprese con un material diferente: las líneas de los forjados y las jácenas, de hormigón; los muros, de ladrillo, los alféizares recubiertos de cerámica de colores; los muros de formas geométricas con recubrimiento vítrico; la carpintería metálica. Un lenguaje propio en el que se sintetizan formas internacionales con las propias tradiciones, y que permite integrar el edificio en su entorno sin renunciar a su modernidad, y que aún hoy en día muestra este difícil equilibrio de integración al entorno y expresión de su propio tiempo". ${ }^{7}$

7 VENDRELL FELICI, Sergio: "Hotel Park, por Antoni de Moragas i Gallissà”, en Arquitectura y Empresa. https://www.arquitecturayempresa.es/noticia/hotel-park-por-antoni-de-moragas-i-gallissa 
Hay que considerar que Moragas fue uno de los impulsores del Grupo R. ${ }^{8}$ Llevó a Barcelona a Bruno Zevi en 1950, en plena Autarquía o a Alvar Aalto en 1951, Pevsner... El colectivo, con el objetivo de promover la arquitectura moderna, se constituye en 1951, integrado por Josep Pratmarsó como presidente; Oriol Bohigas, secretario; Joaquim Gili, tesorero; Antoni de Moragas y Josep Mariares, vocales, junto a Josep Maria Martorell, Jose Antonio Coderch y Manuel Valls. El grupo se mantiene, ganando adeptos entre arquitectos, historiadores, estudiantes y artistas, hasta 1958, en que se disgrega.

\section{GRAN HOTEL DE JACA ${ }^{10}$}

En Jaca, en el prepirineo aragonés, la Caja de Ahorros y Monte de Piedad de Zaragoza, Aragón y Rioja encarga a Lorenzo Monclús Ramírez el nuevo Gran Hotel. Las obras se inician en 1955 y culminan en 1958. Hormigón armado, pizarra en cubiertas y piedra en muros constituyen el inmueble.

El edificio, cuya estudiada orientación es uno de sus valores significativos, mira hacia la Peña Oroel, frente a cuyo rotundo volumen se abren los balcones de los dormitorios en fachada curva de gran plasticidad.

Lorenzo Monclús obtiene el título de arquitecto en 1935, coincidiendo sus iniciales trabajos con la Guerra Civil. Adscrito al Racionalismo, entre sus obras tempranas (1938) destaca el emblemático edificio en Zaragoza para los números 25 y 27 de la calle Cervantes ${ }^{11}$.

Antes de diseñar el proyecto definitivo, Monclús había preparado otro para un concurso restringido convocado en 1947 por la Sociedad Anónima Inmobiliaria Pirenaica. Entonces la propuesta tanto en lo funcional como en lo formal fue diferente. Por una parte, el turismo en los años 40 en Jaca era fundamentalmente estival, mientras que a finales de los 50 aparece con fuerza el esquí como motor para los viajeros al Pirineo. Esto conlleva una modificación sustancial del proyecto; ya que el primero preveía el cierre de parte del establecimiento en

8 URRUTIA, Ángel: Arquitectura española siglo XX, Manuales Arte Cátedra, Madrid, 1997.

9 BONET, Llorenç: Guía de arquitectura de Barcelona, Barcelona, 2004.

10 Revista Nacional de Arquitectura, $\mathrm{n}^{\circ}$ 201, Madrid, septiembre 1958, pp. 9-11.

Existe un excelente trabajo sobre este hotel, escrito por Raimundo Bambó Naya de la Universidad de Zaragoza: "El Gran Hotel de Jaca: Una infraestructura de montaña", en Revista Europea de Investigación en Arquitectura, 2015. El edificio está registrado por DOCOMOMO Ibérico.

11 MARTÍNEZ VERÓN, Jesús: Zaragoza Arquitectura siglo XX. Tipologías, Autopublicación TAGUS, 2015. 
invierno, lo que no se contempla en la propuesta definitiva, cuando ya estaba claro que los deportes de invierno se estaban convirtiendo en el principal atractivo de Jaca. En lo formal se pasa de un edificio con cubierta inclinada de pizarra y torre angular de regusto regionalista a un resultado en el proyecto de los años cincuenta de una gran plasticidad y modernidad.

El hotel, que en la RNA se define como "hotel de viajeros", está como señala Raimundo Bambó, "claramente orientado al turismo, tanto nacional como francés, pues parte del folleto está escrito en ambos idiomas, $\mathrm{y}$ de alto nivel adquisitivo, con vehículo propio, chófer y servicio, para quienes se han habilitado distintas estancias". Al respecto, conviene recordar el interés que el Patronato Nacional de Turismo había concedido a los albergues de carretera, convocando incluso un concurso arquitectónico en 1928 para diseñar estos pequeños alojamientos, que ganarían Arniches y Domínguez, con un proyecto que incluía precisamente un recinto anexo para garaje, taller, dormitorio de conductores y surtidor de gasolina ${ }^{12}$. Y como el mismo patronato durante los años 30 editó numerosos carteles turísticos publicitarios destinados al

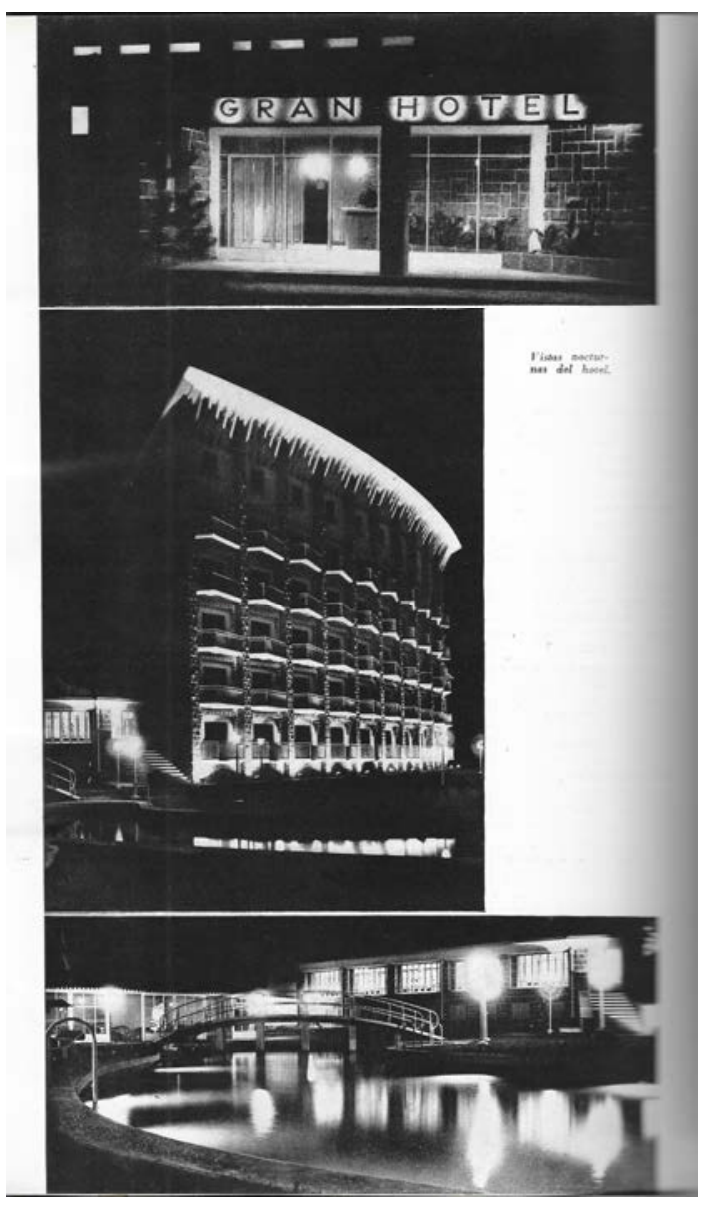
público europeo, con versiones en diferentes idiomas. Alguno de los cuales, como el de Vaquero Palacios para Asturias, muestran un mundo de

12 GUERRERO LÓPEZ, S.: "Carretera, turismo y arquitectura moderna: Los albergues de automovilistas del Patronato Nacional del Turismo (1928-1946)" (JORDÁ SUCH, C., N. PORTAS y J. A. SOSA DÍAZ-SAAVEDRA; dirs.), Valencia, 2003. Fundación DOCOMOMO Ibérico, pp. 69-73 
automovilistas que algunos autores han relacionado con la influencia de Marinetti en Vaquero.

El edificio consta de dos cuerpos. Los dormitorios se emplazan en uno de seis plantas, todas ellas destinadas a habitaciones. El otro cuerpo se dedica a recepción y otros servicios comunes, desarrollándose en planta baja y semisótano. Esta división funcional la explica Monclús en la RNA 13. "Para lograr en las diversas instalaciones del hotel, su fácil colocación en obra, que su entretenimiento sea económico y que no se molesten al hall ni al comedor y galería de invierno, ni en su instalación ni al producirse posibles averías, hemos dispuesto una galería de servicios en planta sótano y hemos separado el cuerpo de edificio de dormitorios del cuerpo de hall y comedor".

Este interés funcional, alejado de presupuestos formalistas tan del gusto de los años precedentes, se evidencia también en el énfasis que pone Monclús en todo lo relacionado con el aislamiento acústico o el mantenimiento. Así, señala: "El pavimento de dormitorios es tablón de pino "flotante" sobre fibra de vidrio, especial, de cinco centímetros de espesor, vuelta perimetralmente hasta la altura del rodapié, con objeto de lograr el mayor aislamiento de ruido posible...".

Y ni una alusión a cuestiones formales o estéticas. Lo que, por cierto, contrasta con las fotografías que ilustran el artículo de la RNA. Pues, junto a una planta general y una perspectiva del cuerpo de dormitorios con jardín y piscina, se muestran una vista de la Peña Oroel enmarcada por la ventana de una habitación y cuatro tomas nocturnas del hotel, de gran belleza y gusto Decó, donde el protagonismo de luces y neones es rotundo. Y dónde por supuesto lo que prima es el juego de claros y sombras que enfatizan la plasticidad del conjunto

\section{HOTEL RECATÍ (VALENCIA) ${ }^{14}$}

Este establecimiento de playa -ya desaparecido- se ubicaba en El Perellonet. Proyectado por Luis Gay ${ }^{15}$, arquitecto que trabajó en Regiones Devastadas, y que reconstruyó templos afectados por la contienda; pero que también acometió varios proyectos de arquitecturas para el ocio. Desde hoteles como el Recatí, el Astoria, el Excelsior de Valencia, el hotel Bayrén de Gandía, el restaurante de los Jardines de Viveros (actual Museo de Ciencias Naturales), el

13 Revista Nacional de Arquitectura, $\mathrm{n}^{\circ}$ 201, Madrid, septiembre 1958, pp. 9-11.

14 Revista Nacional de Arquitectura, nº172, Madrid, abril, 1956. Pp. 14-16.

15 El archivo de Luis Gay fue donado en 2008 por la familia a la Biblioteca Valenciana. 
cine Mónaco de Onda (Castellón). Y todos ellos de una modernidad sorprendente $^{16}$.

El Recatí se extiende longitudinalmente en primera línea de playa. Partiendo de una estructura preexistente de Giménez Cosi, Gay desarrolla su propio planteamiento, logrando un resultado integrado en el paisaje natural circundante.

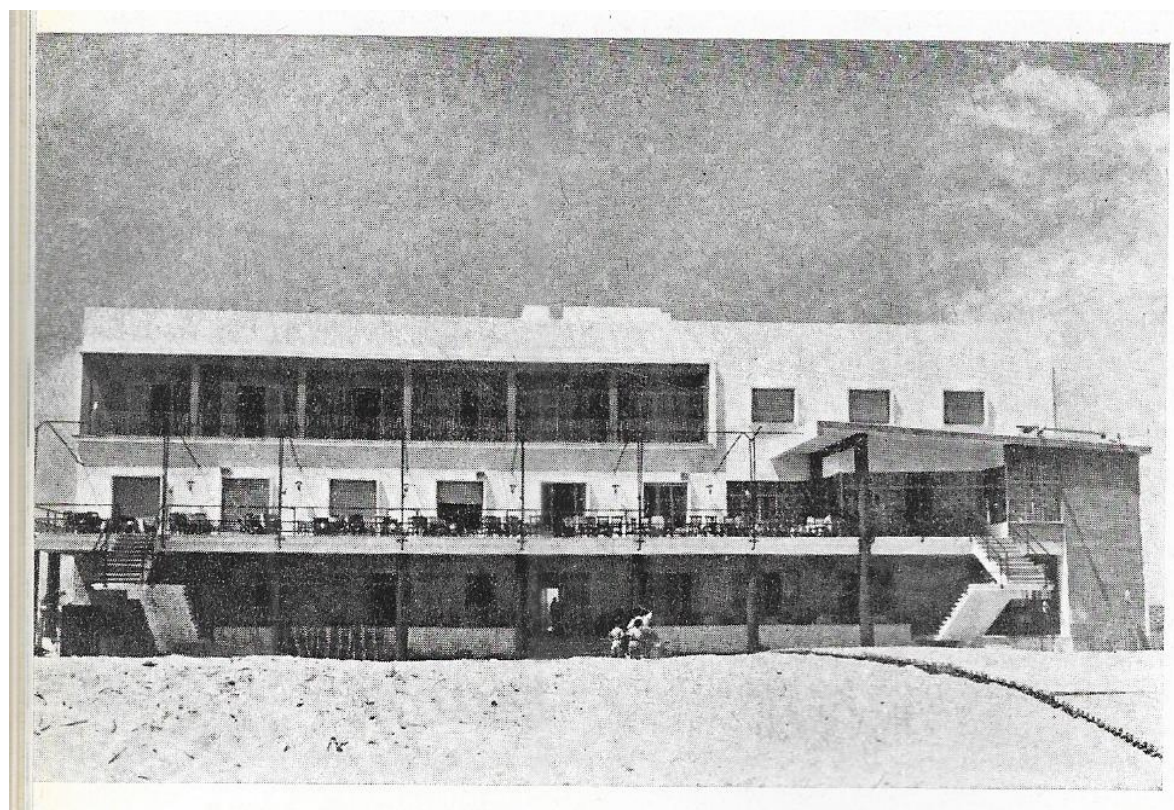

Así, tal como señala Serrano Machuca: "Luis Gay rechaza incluir las diferentes funciones en un único volumen y las separa en distintas edificaciones disminuyendo así su presencia en el medio natural y controlando su impacto. Además, en este conjunto el arquitecto diseña dos elementos singulares que refuerzan ese respeto hacia el paisaje natural y definen, a su vez, la transición entre éste y la zona de actuación. El primero de ellos es la pieza de acceso al conjunto que se formaliza mediante una marquesina horizontal de trazado curvo y un elemento vertical que a modo de hito, permite la perfecta visión anticipada del hotel. El otro elemento notable es la piscina, situada entre el hotel y el mar y rodeada por la arena de la playa, que aparece como un elemento natural y de transición entre el mar y el hotel".

16 SERRANO MACHUCA, D.: "El hotel Recatí: el reencuentro con la modernidad perdida", en II Congreso Pioneros de la Arquitectura Moderna Española: Aprender de una obra.: Actas digitales de las Comunicaciones aceptadas al Congreso. / coord. por Teresa Couceiro Núñez, 2015, pp. 575-585 
El respeto medioambiental articulado en esa decisión de fragmentar los recintos resulta de una modernidad premonitoria en el caso de las construcciones hoteleras españolas. Al respecto, valga pensar en obras de finales del siglo XX como el hotel La Posada de Babel que realiza César Ruiz Larrea en La Pereda, Llanes (Asturias), donde precisamente se logra ampliar el establecimiento inicial, por medio de habilitar pequeñas construcciones exentas ${ }^{17}$.

El interior tiene muy en cuenta la funcionalidad de las estancias. Así, hacia el mar se abren salones, comedor y los treinta dormitorios (veinticinco dobles y cinco individuales). El comedor, además, en primera planta, a fin de obtener la mejor vista del mar. Hay además un cuidado estudio de climatización, para evitar recalentamientos y propiciar ventilación cruzada. Pero también cuida Gay la decoración, el mobiliario y todos los elementos de confort. Para ello cuenta con el diseñador José Martínez Peris.

El edificio aparentemente sencillo, logra evitar la monotonía gracias a un juego de asimetrías tanto horizontales como verticales.

\section{HOTEL BAHÍA PALACE (PALMA DE MALLORCA) ${ }^{18}$}

Francisco Goicochea y Jacinto Vega son los autores de este edificio ubicado en el paseo marítimo de Palma de Mallorca ${ }^{19}$.

El mayor reto para erigir el edificio fue levantar diez pisos sobre un terreno inestable. Para ello, se adoptó un sistema de pilotis que en profundidad llegaban a la roca, a fin de garantizar la cimentación adecuada.

Otra de las preocupaciones, solventada con éxito, fue lograr que la mayoría de las habitaciones dispusieran de vistas al mar. Éstas se distribuyen en siete pisos intermedios. La planta noble ocupa el bajo, el semisótano sirve como zona de servicio. Hay además un ático y zona aneja de tres plantas donde se ubica la sala de fiestas.

17 ADAMS FERNÁNDEZ, Carmen: "Arquitectura y turismo, en torno al hotel. Visiones y propuestas en el último cuarto del siglo XX" en Llanes. Viejas historias, nuevos patrimonios, Llanes, 2003.

18 Revista Nacional de Arquitectura, nº 163 , Madrid, julio 1955, pp. 11-16

19 Seguí Aznar, Miquel. La arquitectura del ocio en Balears. La incidencia del turismo en la arquitectura y el urbanismo, Lleonard Muntaner, Palma, 2001. 
El conjunto se completa con aparcamiento, terrazas y piscina.

La revista dedica un amplio reportaje fotográfico al edificio e interiores, sobre el que existe un interesante trabajo de María Sebastián $^{20}$. Las imágenes fueron realizadas por el prestigioso estudio de Palma, Rul·lan, cuya trayectoria se inicia en 1918 con Gaspar Rul·lan Garcies (18961973) y se prolonga hasta 1981.

Destaca la obra escultórica elegida para el hotel: Horacio Eguía, Jaime Mir y Llinás Riera (fallecido antes de inaugurarse el establecimiento) fueron los elegidos. Asimismo, se dispone

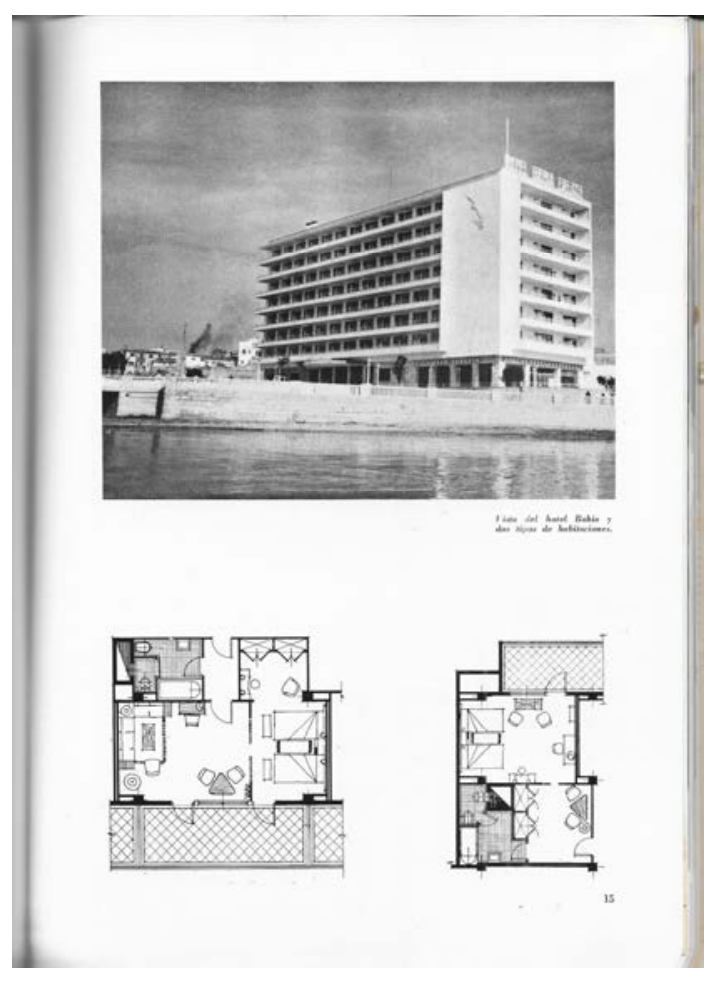
obra pictórica de Pierre François y Carlos Sabrón. Este último era alumno de la Escuela Superior de Arquitectura de Madrid.

\section{HOTEL CÓRDOBA PALACE ${ }^{21}$}

También Francisco Goicochea y Jacinto Vega proyectan el desaparecido edificio de los Jardines de la Victoria, donde ahora se levanta el AC Córdoba Palacio. Como arquitecto residente colaboró José Rebollo, y Atilano Rodríguez fue el aparejador.

Se inauguró en 1956, tras once meses de trabajos, y fue demolido en 2006.

20 Sebastián Sebastián, M., (2016) "'Rul-lan y el hotel Bahía Palace de Palma. Los canales de difusión de la fotografía de arquitectura turística"" En: Alcolea, R.A, Tárrago-Mingo, J., (eds.), Congreso internacional: Inter photo arch Interferencias, celebrado en Pamplona, los días 2 al 4 de Noviembre de 2016, (pp. 202-211)

21 Revista Nacional de Arquitectura, nº180, Madrid, diciembre 1956, pp. 13-16. 
Un total de 125 habitaciones, salón de baile, terrazas y piscina configuraron un inmueble emblemático para la ciudad, que llegó incluso a ceder los terrenos para poder disponer de un establecimiento de esta categoría.

El exterior, sobrio, horizontal, austero incluso, contrata con el lujo de unos interiores de gusto Decó. La decoración corrió a cargo de la firma granadina Martínez Herrera.

Ocho plantas configuran el inmueble. Destaca la noble con un gran vestíbulo, salones, comedor, bar, sala de baile, tiendas, oficinas y salida directa a terrazas y piscina.

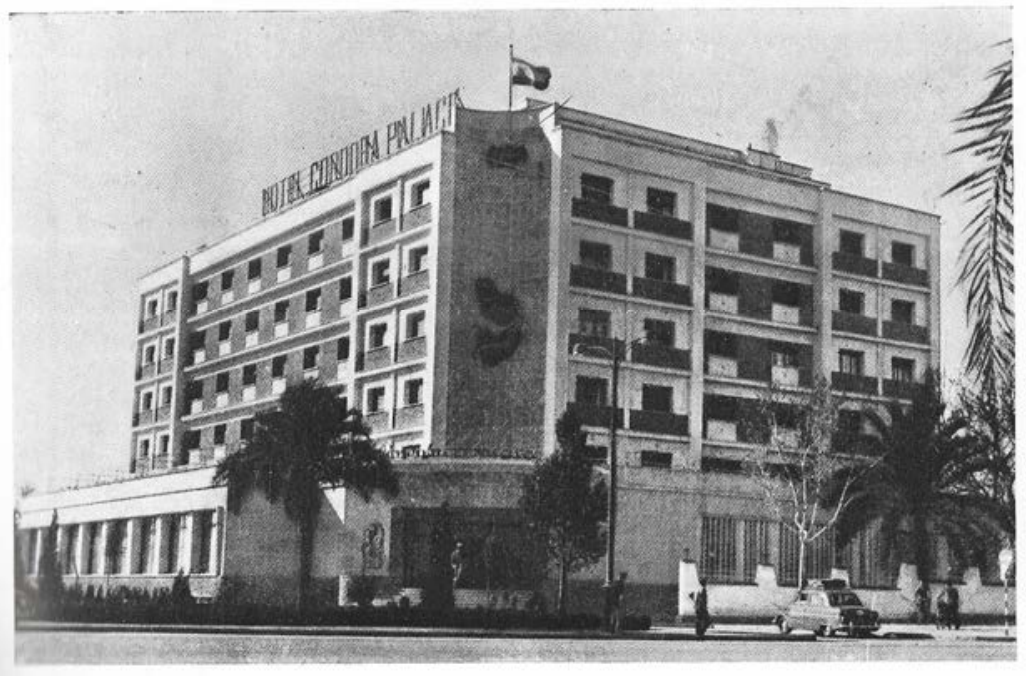

En el momento de su inauguración el periódico $\mathrm{ABC}$ le dedicó una página completa, señalando que "Ya tiene Córdoba el Hotel de rango internacional que necesitaba: Hotel Córdoba Palace. Una inauguración de excepcional importancia. La industria hotelera española acaba de alcanzar uno de sus mejores y valiosos triunfos con la inauguración del Hotel Córdoba Palace, verificada recientemente con los honores debidos a su excepcional importancia en la bella ciudad de la Mezquita. El nuevo Hotel es otro eslabón de la primorosa cadena iniciada con el suntuoso Hotel Bahía Palace, de Palma de Mallorca, y el Hostal del Cardenal, de Toledo, que la prestigiosa empresa Hotursa (Hoteles Turísticos, S. A.) está forjando con tanto acierto para atracción del turismo español e internacional. Y era precisamente en Córdoba, ciudad de historia preclara, andaluza por su gracia, el brío de su corazón y la luz de su cielo, hoy en pleno auge 
y resurgimiento, donde más ostensiblemente se dejaba sentir la necesidad de un hotel moderno".

Es curiosa la descripción que en este diario se realiza de la ornamentación, que al cronista Pedro Cuevas Zarabozo le resulta neoárabe, en una declaración de principios en la que subyace una ideología cercana al casticismo, y que se corresponde poco con la realidad de un claro gusto decó: "En los interiores, del más depurado gusto artístico, se han empleado, hasta donde ha sido posible, materiales y motivos que en su mayoría usaron los árabes; pero, naturalmente, con un concepto de actualidad". Y tanto.

Interesante resulta, en este sentido, la afirmación nacionalista en un momento en que España miraba ya hacia afuera abandonando el periodo autárquico. Así, se señala que "A todo esto hay que agregar que las instalaciones constituyen, dentro del marco nacional, lo más avanzado de la técnica, habiendo evitado en todo momento, y siempre que fue posible, el empleo de materiales de procedencia extranjera, demostración evidente del esfuerzo gigantesco que nuestro país hace en estos momentos por el auge de su industria, ayuda imprescindible para conseguir realizaciones de la categoría de este Hotel". Toda una declaración de principios.

Goicoechea, que termina la carrera -interrumpida por la guerra- en 1947, es autor de numerosos proyectos hoteleros, además de intervenciones industriales notables en colaboración con Cárdenas en la fábrica de ENSIDESA en Avilés. Primero en colaboración con el arquitecto Jacinto Vega, con quien monta un estudio, y después muy ligado a la Empresa Meliá. Con Jacinto Vega realizó varios hoteles en Andalucía y Baleares. Además del Córdoba Palace, proyectó el Bahía Palace, en 1955 en Palma de Mallorca. También diseñó otros hoteles en Torremolinos, como el Tritón, el Pez Espada o el Siroco. En 1964 la empresa Meliá crea una oficina técnica que pasa a dirigir Goicoechea desde el principio. Allí se encarga de las grandes obras de la empresa, contando con la estrecha colaboración de los arquitectos Veguilla y Nestares. De esa oficina surgen numerosas obras en Madrid. En 1970 realizó el estudio volumétrico de la manzana que queda entre la calle Orense y Capitán Haya; allí proyecta y construye el Meliá Castilla (1970), por entonces el hotel más grande de Europa, con sus mil habitaciones. Para esta obra, Goicoechea y su equipo proyectaron un muro-cortina de hormigón en la fachada que por su disposición y tamaño resultaba novedoso. Más adelante, realizará el Meliá Alicante (1972-73) 22 .

22 BOGAERTS, Jorge: "Cárdenas y Goicoechea y sus proyectos para Ensidesa”, LNE, Nueva Quintana, Oviedo, 15-5-2007. 


\section{HOTEL TIROL (MADRID) $)^{23}$}

El arquitecto gallego Santiago Rey Pedreira ${ }^{24}$ firma el proyecto para el Hotel Tirol en Madrid.

Destaca en este inmueble la apuesta por un tipo de fachada muy característica entre 1955 y 1960, denominada $\mathrm{Fa}$ chada Encintada ${ }^{25}$ que implica "un culto a la sinceridad constructiva con un alcance tal en lo compositivo arquitectónico que la práctica mayoría de los arquitectos de calidad de la época no pudieron sustraerse a una moda que significaba modernidad técnica", tal como señala Ros García. Aquí, según se explica en la RNA "toda la estructura es de hormigón armado por pilares situados en los límites

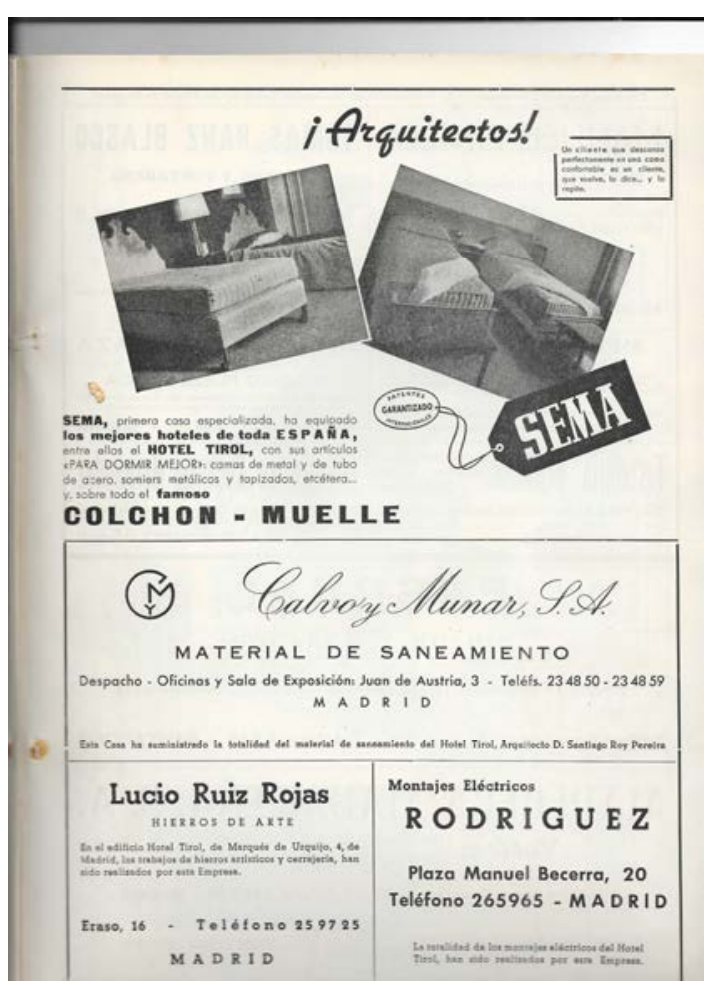
del solar, excepto en la fachada, que se retiran $1,25 \mathrm{~m}$ para obtener la mayor diafanidad exterior".

La descripción que en la revista se realiza del edificio es puramente técnica y constructiva. No hay concesión alguna a lo ornamental, notándose el creciente interés en estos años por el progreso en uso de materiales y nuevas tecnologías, y el olvido de toda la parafernalia ideologizada del Régimen aplicada a la arquitectura.

No obstante, en la RNA encontramos anuncios de prestigiosas firmas de decoración y mobiliario que se encargaron del interior del hotel. Así, las camas y colchones son de la casa SEMA, que se publicita en el mismo número de la revista como la marca que "ha equipado los mejores hoteles de toda España,

23 Revista Nacional de Arquitectura, $\mathrm{n}^{\circ}$ 178, Madrid, octubre 1956, pp.40-42.

24 Luis Walter Muñoz Fontenla ha realizado una excelente Tesis Doctoral sobre Rey Pedreira, leída en la ETSA de Coruña en 2012.

25 ROS GARCÍA, J.M.: "La fábrica de doble hoja en Madrid, un siglo de cerramiento moderno" Informes de la Construcción, Vol. 56, n 495, enero-febrero 2005, pp. 57.-71., 
entre ellos el Hotel Tirol". La cerrajería y los hierros artísticos fueron realizados por Lucio Ruiz Rojas de Madrid.

El edificio se estructura en cuatro alas distribuidas en una planta en $\mathrm{H}$, lo que permite ventilación e iluminación garantizada a todas las habitaciones, al modo de los rascacielos cruciformes del Movimiento Moderno.

Hay que considerar que Rey Pedreira es uno de los mejores exponentes del racionalismo en Galicia, autor de edificios tan emblemáticos como el Estadio de Riazor (1944) o anteriormente el mercado de San Agustín de la Coruña (1932) en colaboración con Antonio Tenreiro Rodríguez. El mercado con su cubierta parabólica fue símbolo de la modernidad arquitectónica en Galicia y está incluido en DOCOMOMO.

\section{HOTEL ACAPULCO EN PLAYA DEL ARENAL. MALLORCA ${ }^{26}$}

La RNA dedica un espacio común en 1960 a dos hoteles que se levantan en sendas playas de la isla de Mallorca. El Acapulco en El Arenal, y el Molins en la cala homónima.

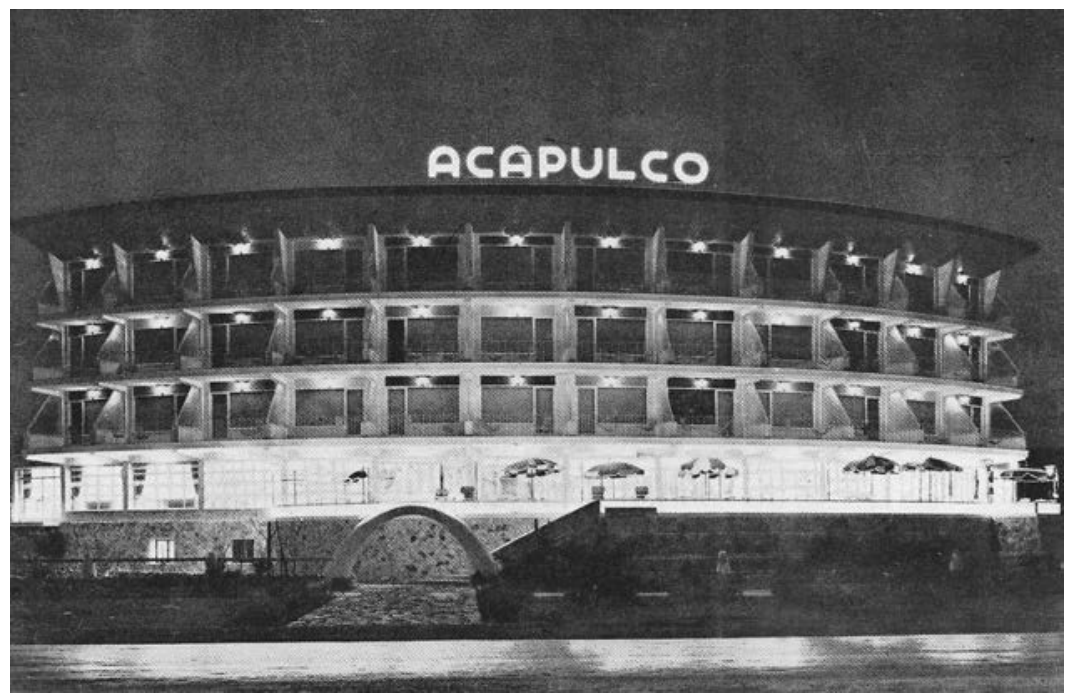

Pese a las diferencias de emplazamiento de los dos establecimientos (una cala del norte, con topografía abrupta y un área llana y amplia), se destacan las comunes dificultades de ambos proyectos: "armonizar las necesidades del

26 Revista Nacional de Arquitectura, año 4, nº 20, Madrid, agosto 1960, pp.37-40. 
programa con las ideas de los propietarios, sobre todo si éstos son varios a la vez, como sucede en el presente caso que son tres para cada hotel". Y se subraya, en inequívoca declaración de principios: "Queremos decir que existe una gran dificultad en estas obras para hacer prevalecer las ideas del arquitecto; las obras se han dirigido al pie de las mismas para enfrentarnos a la oposición".

Esto nos marca una forma de entender la figura del arquitecto, por parte de ellos mismos, como emisarios de un deber divino. Al modo en que King Vidor hace moverse a Gary Cooper, en un mundo de empresarios sin escrúpulos ni sensibilidad, en El Manantial. Aunque se reconoce la necesidad de consensuar, como evidencia que el Acapulco "está ambientado en el interior con motivos mejicanos, complaciendo los deseos de la propiedad". Señalar, eso sí, que entre las variadas fotografías que se publican, ninguna da prueba de ellos, en un claro toma de postura intelectual al respecto ${ }^{27}$.

El Hotel Acapulco, obra del arquitecto mallorquín Rafael Llabrés y Fuster, presenta una fachada al mar de 58 metros. El principal objetivo aquí era lograr el máximo de habitaciones con vistas al mar. Para ello, el proyectista curva la fachada, obteniendo doce dormitorios dobles hacia la playa, y sólo seis en la

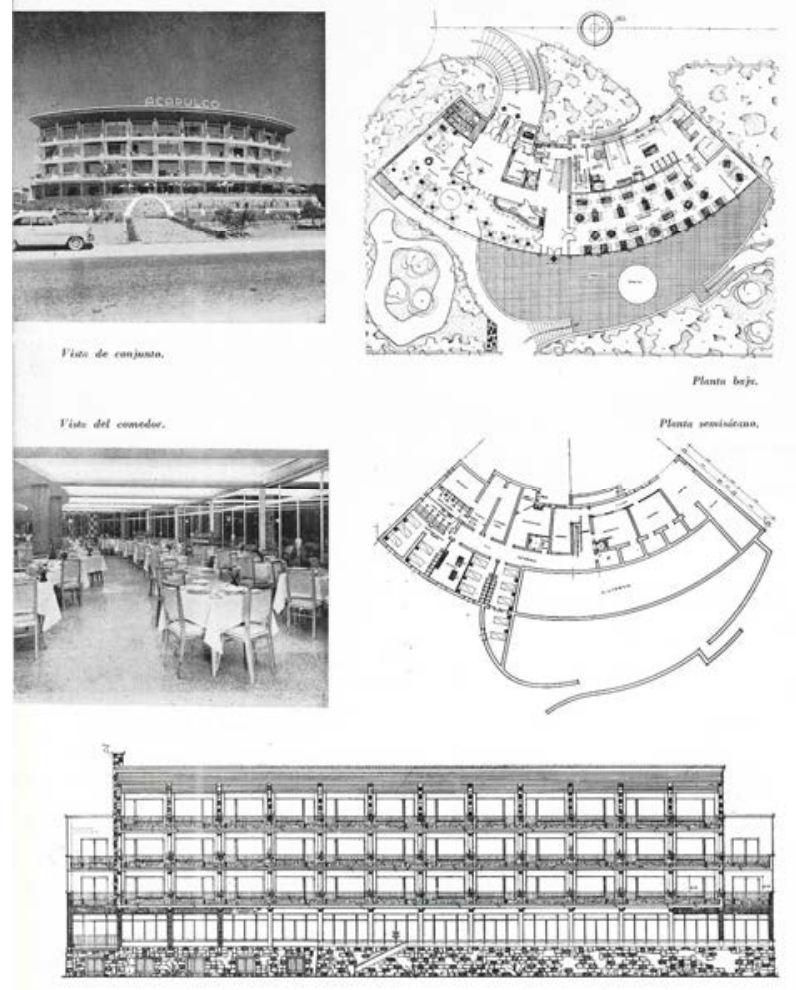

27 Este tipo de encargos muy concretos e incluso personales, los hemos evidenciado en otros establecimientos hoteleros. Así por ejemplo, mucho más cerca de nuestro tiempo en el Hotel Abba de Gijón (2005), los arquitectos Antonio Fernández Morán y Luis Mingo Macías supieron realizar una interesante abstracción en un encargo en que el tema marinero, náutico...era de imprescindible resolución. ADAMS, Carmen: "Modernidad y sostenibilidad en la construcción hotelera. Realidades y proyectos", en ÁLVAREZ, Soledad: El waterfront de Gijón (1895-2005). Nuevos patrimonios en espacio público, Asturias, Eikasía, 2009. 
parte posterior desde donde se puede apreciar el bosque. En los extremos del inmueble se ubican las cuatro suites, desde las que se puede contemplar tanto el mar como la masa arbórea.

La estructura es de hormigón armado, cimentándose sobre la arena, ya que se trata de material comprimido que permite esto.

Llabrés ${ }^{28}$ es uno de los exponentes de la arquitectura del turismo en Mallorca. Autor de la urbanización Cala Azul (1960) y director de Sometimes en Playa de Palma.

\section{HOTEL MOLINS EN MALLORCA ${ }^{29}$}

El otro edificio al que se dedica el artículo es el levantado también por Rafael Llabrés, en este caso con proyecto compartido con J. María Llaurado en una cala del norte de Mallorca. El inmueble, cuya construcción se prolongó desde finales de 1955 hasta primavera de 1957, se encarama sobre la ladera abrupta, con acceso desde la parte inferior y también desde la superior. Se tienen en cuenta tanto el viento del norte que se evita, como las vistas sobre Cala de San Vicente, que se buscan.

En la zona alta se ubica el vestíbulo, y el acceso de viajeros a recepción y a los dormitorios, todos ellos con vistas al mar. En la fachada al océano, el acceso por planta baja permite acceder a la terraza y bar.

Se resalta que, gracias a un pozo de agua dulce perforado junto al mar, se logró el necesario abastecimiento de agua potable para el hotel.

La elección de modelos funcionales, sobrios y de gran interés para la arquitectura hotelera en estos años tiene otros ejemplos destacados en Baleares, como el Hotel de Mar en Palma, obra de José Antonio Coderch y Manuel Valls o la Ciudad Blanca de Alcudia de Sáenz de Oiza ${ }^{30}$.

28 Llabrés es autor del edificio Palma, en la capital de Mallorca. Obra erigida entre 1958 y 1959 y catalogada en DOCOMOMO.

29 Revista Nacional de Arquitectura, año 4, no 20, Madrid, agosto 1960, pp.37-40.

30 Sobre las arquitecturas turísticas en Baleares, sus luces y sombras, existe numerosa bibliografía, como el interesante estudio de Miguel Seguí, publicado en 2001 por Lleonard Muntaner, bajo el título: La arquitectura del ocio en Baleares. La incidencia del turismo en la arquitectura y el urbanismo o el estudio publicado en por Luis Corral Juan, Gabriela Kacelnik y Antonio Ramis Ramos: "Islas Baleares: arquitecturas para el turismo" en Actas IV Congreso. Fundación DOCOMOMO Ibérico Arquitectura moderna y Turismo: 1925-1965, Valencia, 2003. 

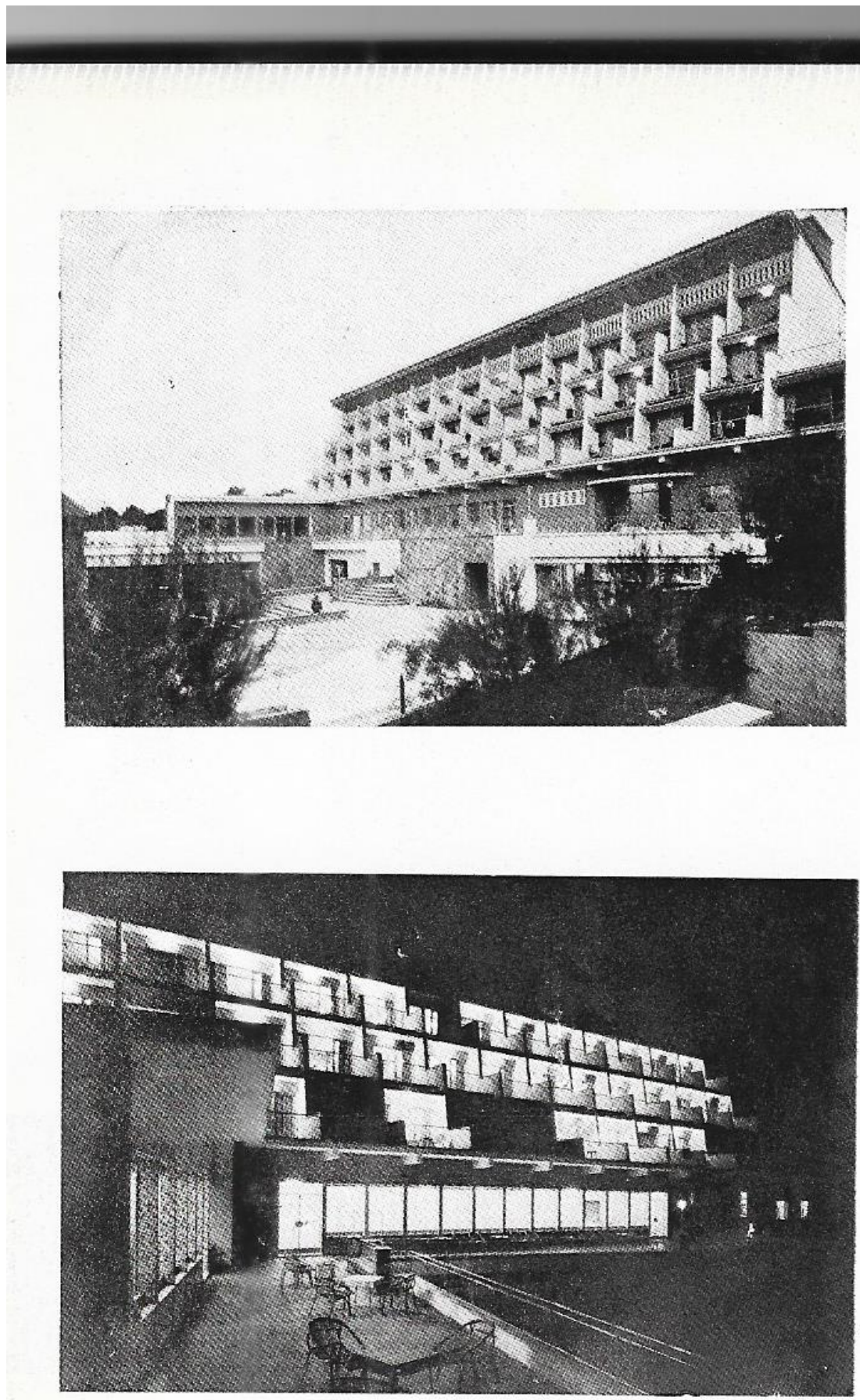

NORBA. Revista de Arte, Vol. XXXIX (2019) 111-132, ISSN: 0213-2214 


\section{Conclusiones}

Tras este recorrido por los edificios hoteleros a los que la Revista Nacional de Arquitectura presta atención a lo largo de la década de los 50 del siglo XX se evidencia una apuesta por el Funcionalismo y los modelos internacionales, frente a las propuestas constructivas regionalistas o ampulosas de la década anterior. Se analizaron 8 hoteles, 4 de ellos en la costa mediterránea, uno de montaña, y tres urbanos. En todos los casos se muestra un interés por cuestiones de higiene, ventilación, confortabilidad, adaptación al entorno o aspectos meramente constructivos. No obstante, es de destacar que en los interiores se cuida al detalle un mobiliario acorde con las tendencias de ese retorno al lujo del Decó que se experimenta en los años 50 (y que, por cierto, recupera actualmente la arquitectura hotelera de principios del siglo XXI).

El interés por dotar a los hoteles de habitaciones con vistas y otras comodidades para el turista que empieza a llenar las costas mediterráneas en busca de sol y playa o que empieza a demandar lugares cómodos para alojarse durante la práctica de deportes de invierno se hace patente en los ejemplos mencionados.

En lo referente a los establecimientos urbanos, tanto en el caso de Barcelona como en el de Madrid, se pretende comodidad y funcionalidad para un viajero de paso, mientras que, en el caso de Córdoba, la propuesta está claramente orientada a un turista que exige calidad y lujo; un turista culto que se acerca a contemplar la mezquita y que luego busca todos los servicios para el descanso.

Así, se aprecia cómo la construcción hotelera en la España de finales de los años 50 del siglo XX muestra una clara apuesta por el funcionalismo y la modernidad. Se evidencia -a través de la Revista Nacional de Arquitectura- que la arquitectura turística se adscribe en esta etapa a los movimientos internacionales del momento. Esto se hace patente además por la aparición de ejemplos españoles en catálogos europeos, junto a hoteles de reconocida calidad arquitectónica de otros países. Modernidad entendida como sobriedad funcional en los exteriores; lo que contrata con interiores donde se recrea un gusto Decó lujoso. Así, las tendencias vanguardistas están presentes en España desde la posguerra, lo que demuestra cómo las panoplias y regresiones de la Autarquía no impidieron el mantenimiento de una línea innovadora en la arquitectura nacional que venía de la etapa anterior. 


\section{REFERENCIAS BIBLIOGRÁFICAS}

\section{FUENTES}

Revista Nacional de Arquitectura, año 4, nº 20, Madrid, agosto 1960, pp.37-40. Revista Nacional de Arquitectura, ${ }^{\circ}$ 201, Madrid, septiembre 1958, pp. 9-11. Revista Nacional de Arquitectura, $\mathrm{n}^{\circ}$ 163, Madrid, julio 1955, pp. 11-16 Revista Nacional de Arquitectura, $\mathrm{n}^{\circ} 178$, Madrid, octubre 1956, pp.40-42. Revista Nacional de Arquitectura, nº180, Madrid, diciembre 1956, pp. 13-16.

\section{BIBLIOGRAFÍA}

ADAMS FERNÁNDEZ, Carmen: "Arquitectura y turismo, en torno al hotel. Visiones y propuestas en el último cuarto del siglo XX" en Llanes. Viejas historias, nuevos patrimonios, Llanes, 2003.

ADAMS, Carmen: "Modernidad y sostenibilidad en la construcción hotelera. Realidades y proyectos", en ÁLVAREZ, Soledad: El waterfront de Gijón (1895-2005). Nuevos patrimonios en espacio público, Asturias, Eikasía, 2009.

BAMBÓ NAYA, R.: "El Gran Hotel de Jaca: Una infraestructura de montaña", en Revista Europea de Investigación en Arquitectura, 2015.

BOGAERTS, Jorge: "Cárdenas y Goicoechea y sus proyectos para Ensidesa", LNE, Nueva Quintana, Oviedo, 15-5-2007.

BONET, Llorenç: Guía de arquitectura de Barcelona, Barcelona, 2004.

DE MORAGAS GALLISÁ, Antonio: "Hotel Park en Barcelona", Revista Nacional de Arquitectura $\mathrm{n}^{\circ}$ 182, Madrid, Febrero, 1957

GUERRERO LÓPEZ, S.: "Carretera, turismo y arquitectura moderna: Los albergues de automovilistas del Patronato Nacional del Turismo (19281946)" (JORDÁ SUCH, C., N. PORTAS y J. A. SOSA DÍAZ-SAAVEDRA; dirs.), Fundación DOCOMOMO Ibérico, Valencia, 2003, pp. 69-73

MARTÍNEZ VERÓN, Jesús: Zaragoza Arquitectura siglo XX. Tipologías, Autopublicación, TAGUS, 2015.

PELLEJERO MARTÍNEZ, Carmelo: "La política turística en la España del siglo XX: una visión general”, en Historia Contemporánea 25, 2002, pp. 233-265

PETERS, Paulhans: Hoteles y Colonias veraniegas, Guatavo Gili, Barcelona, Munich, 1970.

ROS GARCÍA, J.M.: "La fábrica de doble hoja en Madrid, un siglo de cerramiento moderno" Informes de la Construcción, Vol. 56, no 495, enero-febrero 2005, pp. 57.-71. 
SEBASTIÁN, M., "Rul·lan y el hotel Bahía Palace de Palma. Los canales de difusión de la fotografía de arquitectura turística" En: Alcolea, R.A, Tárrago-Mingo, J. (eds.), Congreso internacional: Inter photo arch Interferencias, celebrado en Pamplona, los días 2 al 4 de Noviembre de 2016, (pp. 202-211)

SEGUÍ, Miguel: : La arquitectura del ocio en Baleares. La incidencia del turismo en la arquitectura y el urbanism, Lleonard Muntaner, Palma de Mallorca, 2001

SERRANO MACHUCA, David: "El hotel Recatí: el reencuentro con la modernidad perdida", en II Congreso Pioneros de la Arquitectura Moderna Española: Aprender de una obra.: Actas digitales de las Comunicaciones aceptadas al Congreso. / coord. por Teresa Couceiro Núñez, 2015, pp. 575585

URRUTIA, Ángel: Arquitectura española siglo XX, Manuales Arte Cátedra, Madrid, 1997.

VVAA: Actas IV Congreso. Fundación DOCOMOMO Ibérico Arquitectura moderna y Turismo: 1925-1965, Valencia, 2003.

VVAA: Las revistas de arquitectura (1900-1975). Crónicas, manifiestos, propaganda. Actas del Congreso Internacional de Historia de la Arquitectura Española, Pamplona, 2012.

VENDRELL FELICI, Sergio: "Hotel Park, por Antoni de Moragas i Gallissà", en Arquitectura y Empresa. https://www.arquitecturayempresa.es/noticia/hotelpark-por-antoni-de-moragas-i-gallissa

Carmen Adams Fernández

Departamento de Historia del Arte y Musicología Área de Historia del Arte Universidad de Oviedo C/ Amparo Pedregal s/n 33011 Oviedo (España) https://orcid.org/0000-0003-1230-6528 adamsf@uniovi.es 